\title{
Validity of heart rate indexes to assess wheeling efficiency in patients with spinal cord injuries
}

\author{
ACB Coutinho, FR Neto and PSS Beraldo
}

Study design: Cross-sectional study.

Objectives: To validate heart rate (HR) indexes for the evaluation of energy expenditure during wheelchair propulsion in people with spinal cord injury (SCI).

Setting: SARAH Rehabilitation Hospital Network-Brasilia, Brazil.

Methods: Forty-eight men aged $29.0 \pm 7.8$ years with a SCI between $\mathrm{C} 6$ and $\mathrm{L} 3$ causing complete motor impairment were enrolled in the study. The assessment consisted of 5 min of rest while seated in the wheelchair, followed by 5 min of wheelchair propulsion at a self-selected comfortable speed. The main outcomes measured were oxygen consumption, HR, physiological cost index (PCI), total heart beat index (THBI) and propulsion cardiac cost index (PCCI).

Results: Using oxygen uptake as gold standard, the highest correlations were found between this and $\mathrm{PCCl}(r=0.59, P<0.001$, $95 \%$ confidence interval $\mathrm{Cl}$ ) $0.36-0.75)$ and THBI $(r=0.58, P<0.001,95 \% \mathrm{Cl} 0.36-74.0)$, independently of the injury level. The $\mathrm{PCl}$ had the lowest correlation coefficient $(r=0.38, P<0.01,95 \% \mathrm{Cl} 0.11-0.60)$. Spearman correlation analysis showed that the indexes mostly associated with lesion level were $\mathrm{PCCl}(\rho=-0.531 ; P<0.001 ; 95 \% \mathrm{Cl}-0.708$ to -0.291$)$ and $\mathrm{THBl}$ ( $\rho=-0.524 ; P<0.001 ; 95 \% \mathrm{Cl}-0.704$ to -0.282 ).

Conclusions: Both $\mathrm{THBI}$ and $\mathrm{PCCl}$ seem to be valid measures for assessing energy expenditure. Both indexes showed a coherent correlation with the spinal injury level.

Spinal Cord (2014) 52, 677-682; doi:10.1038/sc.2014.107; published online 8 July 2014

\section{INTRODUCTION}

Dramatic lifestyle changes are common after a spinal cord injury (SCI), being the inability to walk often one of them. Most injured individuals use wheelchairs as a form of displacement, and most wheelchairs used are manually propelled. ${ }^{1-3}$ However, manual wheelchair propulsion is considered to be a strenuous activity in terms of expended energy and demanded biomechanics. ${ }^{4}$ Consequently, the assessment of energy cost during wheelchair propulsion is an important outcome during rehabilitation programs for patients with SCI, as it allows for an objective evaluation of physical fitness, in addition to determining the clinical effectiveness of important interventions, such as adaptations and an appropriate choice of wheelchair, as well as physical training.

The measurement of oxygen uptake consists of the gold standard assessment method. However, it is uncomfortable for patients and involves sophisticated and expensive equipment, requiring restricted and specialized handling. ${ }^{5}$ Other methods used to estimate energy expenditure are based on cardiac activity. ${ }^{6}$ Heart rate (HR) and oxygen uptake are linearly correlated during aerobic exercise. ${ }^{7}$ This correlation has been demonstrated with regard to healthy adults, ${ }^{7}$ individuals with cerebral palsy or healthy children ${ }^{8}$ and individuals with SCI, all of them while walking. ${ }^{9-11}$

Various reports in the literature have suggested the use of indexes to measure the displacement efficiency using HR as an alternative method of assessing energy cost. It is understood by efficiency here refers to the ratio of the work done or energy developed by one individual while moving on a wheelchair. The indexes proposed include the physiological cost index (PCI), ${ }^{6}$ the total heart beat index $(\mathrm{THBI})^{10}$ and the propulsion cardiac cost index (PCCI). ${ }^{12}$ However, in the literature, we did not find any validation studies of these indexes with regard to estimating energy expenditure during wheelchair propulsion in patients with SCI.

Thus this study had as its main purpose the validation of these indexes according to two aspects: criterion and construct. In the first case, indexes were related to simultaneous measurements of oxygen consumption and, in the second case, to the level of the spinal lesion. We expect to find better results with the indexes that compute only the HR variations during exercise (THBI and PCCI), considering the chronotropic impairment response of SCI patients.

\section{MATERIALS AND METHODS}

Ethics approval

This study was approved by the ethics committee of the SARAH Network of Rehabilitation Hospitals, and all patients provided an informed written consent to participate in the study.

\section{Participants}

This cross-sectional study assessed a convenience sample of hospitalized manual wheelchair users with traumatic SCI who were participating in a rehabilitation program in the Brasilia units (Center and North Lake) 
of the SARAH Network of Rehabilitation Hospitals from December 2004 to July 2005.

Inclusion criteria were male sex, diagnosis of traumatic SCI, clinical stability, manual wheelchair usage and ability to push the wheelchair for at least $5 \mathrm{~min}$ at a self-selected comfortable speed. Patients with cardiovascular and pulmonary abnormalities or who were using cervical and trunk orthosis were excluded from the study.

All participants had motor complete lesion (American Spinal Injury Association Impairment Scale (AIS) A or B). ${ }^{13}$ Lesion levels ranged from C6 to L3, stratified into three groups: tetraplegia (TP; C6-C8), high paraplegia (HP; T1-T6) and low paraplegia (LP; T7-L3). Previous physical activity level was classified as sedentary (no physical activity routine) or active (physical activity performed at least three times a week). ${ }^{14}$ For this classification, we did not consider the time dedicated to physical therapy or activities of daily living. Only one patient in each group had their physical activity level classified as 'active'. It is worth highlighting that among tetraplegic patients from C6 level there is key muscle group that performs wrist extension (extensor carpi radialis), as well as partial supinator innervation, pronator teres and latissimus dorsi, which permits independence of manual wheelchair.

All participants were medically screened, and medication usage was similar in the three groups.

\section{Procedures}

Patients were instructed to refrain from eating or smoking for $3 \mathrm{~h}$ and to empty the bladder before the assessment, which was always conducted in the afternoon, indoors, without air-conditioning. Relative humidity ranged between $50 \%$ and $90 \%$, and temperature between 26 and $30{ }^{\circ} \mathrm{C}$.

Patients used their own manual wheelchairs or those provided by the rehabilitation centre with a mean weight of $17.1 \mathrm{~kg}$. Before the assessment, the tire pressure was set to the manufacturer's recommendation (36-65 pounds per square inch or $2.2-4.5$ bar). Patients chose the circuit direction so they could have their stronger or dominant upper limb towards the outside of the track. They were allowed to adjust the wheelchair rim (pins or rubber tubing) or their gloves for improved grip, in order to match their usual conditions.

The assessment consisted of $5 \mathrm{~min}$ of rest in a sitting position on the wheelchair, followed by $5 \mathrm{~min}$ of a self-selected comfortable speed for propulsion in closed paths (with diameters of 30 or $70 \mathrm{~m}$ ). The number of completed laps multiplied by the course perimeter determined the total distance travelled. Propulsion velocity $\left(\mathrm{m} \mathrm{min}^{-1}\right)$ was calculated by the ratio between the distance travelled and total time. Oxygen uptake and HR were concomitant and continuously recorded during assessment. Oxygen uptake was measured using a portable analyser (Cosmed K4b2, Rome, Italy), which was able to measure both oxygen consumption and carbon dioxide production, breath by breath. The equipment was calibrated at the beginning of each assessment session. HR was recorded every $5 \mathrm{~s}$ as beats $\min ^{-1}$, using a portable heart monitor (Polar S810, Kempele, Finland).

The formulae listed in Table 1 were used for the calculations of the HR indexes, as originally proposed.

\section{Statistical analysis}

Values are described as mean \pm s.d. and $95 \%$ confidence intervals (95\% CI). For intra-group analysis, we used the paired $t$-test comparing rest and exercise. For inter-group analysis, the means were compared using the one-way analysis

Table 1 Equations for the indexes of energy expenditure calculation

\begin{tabular}{|c|c|}
\hline indexes & Formula \\
\hline Physiological Cost Indexa (PCI) & $\frac{\text { Exercise } H R-\text { Basal HR }}{\text { Propulsion speed }}=$ beats $\mathrm{m}^{-1}$ \\
\hline Total Heart Beat Index ${ }^{\mathrm{b}}$ (THBI) & $\frac{\text { Exercise Total Heart Beat }}{\text { Distancetraveled }}=$ beats $\mathrm{m}^{-1}$ \\
\hline Propulsion Cardiac Cost Index ${ }^{c}(\mathrm{PCCl})$ & $\frac{\text { Exercise HR }}{\text { Propulsion speed }}=$ beats $\mathrm{m}^{-1}$ \\
\hline
\end{tabular}

Abbreviations: $\mathrm{HR}$, heart rate; $\mathrm{m}$, meter.

a Heart rates obtained from the last $2 \mathrm{~min}$, in resting (basal) or propulsion.

bIt was considered the totality of heart beats registered during the entire propulsion phase.

${ }^{c}$ Mean heart rate in the whole exercise phase. of variance, and in the case of significance, a post hoc analysis, using the Bonferroni test, was carried out to avoid type I error.

For the validation of indexes, we performed two analyses. First, for criterion validity (concurrent), indexes were related with oxygen uptake (gold standard) using Pearson's correlation coefficient $(r)$. To avoid inference errors, we considered the possible effect of co-linearity between indexes. Because PCI, PCCI and oxygen cost were calculated by dividing by the same denominator (propulsion speed), only the numerators were considered. In the case of THBI, despite of the fact that its denominator (distance travelled) was different from the denominator of oxygen cost (speed), we considered the possibility of spurious results because distance is used for the calculation of speed. Thus it was necessary to take into account the accumulated oxygen consumption $\left(\mathrm{ml} \mathrm{kg}^{-1}\right)$ during the entire exercise, rather than during each minute.

To check construct validity, we investigated the relationship between the indexes and lesion level, using Pearson's $(r)$ and Spearman's $(\rho)$ correlations. We transformed lesion level into a numeric ordinal variable, assigning values to each level (for example, for levels C4, C5 and C6, we used the values 1, 2 and 3, and for L1, L2 and L3, the values 18, 19 and 20, respectively).

The statistical packages Statview for Windows (version 5.0.1; SAS Institute Inc., Cary, NC, USA) and SPSS (version 13.0; SSPS Inc.) were used to analyse the data. The level of statistical significance was set at $P<0.05$.

\section{RESULTS}

Two patients, from the total group of 50 patients, were excluded, because we failed to capture their HR. We did not find any differences in demographic characteristics between the groups (Table 2).

Patients travelled a mean distance of $293 \mathrm{~m}( \pm 84.1)$ at a mean speed of $55.1 \mathrm{~m} \mathrm{~min}^{-1}\left( \pm 15.8 \mathrm{~m} \mathrm{~min}^{-1}\right)$. Participants from the TP groups travelled a shorter distance at a slower speed $(231 \pm 67.7 \mathrm{~m}$ and $43 \pm 12.6 \mathrm{~m} \mathrm{~min}^{-1}, \quad P<0.001$, respectively) when compared with

Table 2 Baseline characteristics

\begin{tabular}{|c|c|c|c|c|}
\hline & $\begin{array}{c}\text { Tetraplegia } \\
\text { C6-C8 } \\
(\mathrm{N}=15)\end{array}$ & $\begin{array}{c}\text { High paraplegia } \\
\begin{array}{c}\text { T1-T6 } \\
(\mathrm{N}=17)\end{array}\end{array}$ & $\begin{array}{l}\text { Low paraplegia } \\
\begin{array}{c}T 7-\angle 3 \\
(\mathrm{~N}=16)\end{array}\end{array}$ & $\begin{array}{c}A / l \\
C 6-L 3 \\
(N=48)\end{array}$ \\
\hline \multicolumn{5}{|c|}{ Age (years) } \\
\hline Mean & 27.3 & 29.2 & 30.5 & 29.1 \\
\hline S.d. & 5.8 & 8.4 & 8.9 & 7.8 \\
\hline Range & $21.5-45.3$ & $18.7-46.8$ & $16.7-46.0$ & $16.7-46.8$ \\
\hline \multicolumn{5}{|c|}{ Time of injury (years) } \\
\hline Mean & 2.9 & 1.8 & 2.6 & 2.4 \\
\hline S.d. & 2.3 & 2.0 & 3.9 & 2.8 \\
\hline Range & $0.5-7.2$ & $0.4-8.8$ & $0.4-14.4$ & $0.3-14.4$ \\
\hline \multicolumn{5}{|c|}{ Weight (kg) } \\
\hline Mean & 64.93 & 70.0 & 71.1 & 68.8 \\
\hline S.d. & 10.6 & 14.6 & 13.3 & 13.0 \\
\hline Range & $49.1-86.5$ & 53.9-111.1 & 49.8-99.4 & $49.1-111.1$ \\
\hline \multicolumn{5}{|c|}{ Span length ${ }^{\mathrm{a}}(\mathrm{m})$} \\
\hline Mean & 1.78 & 1.76 & 1.81 & 1.79 \\
\hline S.d. & 0.08 & 0.11 & 0.06 & 0.09 \\
\hline Range & $1.64-1.89$ & $1.61-2.10$ & $1.73-1.91$ & $1.61-2.1$ \\
\hline \multicolumn{5}{|c|}{$B M I^{b}\left(k g m^{-2}\right)$} \\
\hline Mean & 20.6 & 22.1 & 21.6 & 21.5 \\
\hline S.d. & 3.6 & 3.3 & 4.1 & 3.6 \\
\hline Range & $14.3-26.7$ & $16.6-28.0$ & $15.9-30.7$ & $14.3-30.7$ \\
\hline
\end{tabular}

Abbreviation: BMI, body mass index.

${ }^{a}$ Calculated by twice the measure between the sternal notch and the middle finger, with the arm extended.

${ }^{b}$ BMI was calculated using the span length 
those from the LP or HP groups. There was no difference between the LP and HP groups considering distance and speed (Table 3).

During exercise, there was an increase of 2.4 times in mean oxygen consumption in relation to baseline values, regardless of lesion level. Patients with TP consumed less oxygen than those with LP $(P<0.017)$, either at rest or during exercise. However, oxygen consumption by meters moved (oxygen cost) was greater in patients with TP $(P<0.017)$. On average, resting $\mathrm{HR}$ was of $84.2 \pm 14.7$ beats $\min ^{-1}$, with no difference between the groups. During exercise, participants had a mean increase of 30 beats $\mathrm{min}^{-1}$. HR alone was not different between the groups, either at rest or during exercise. The averages of HR indexes were higher in the TP group compared with the LP group only. No HR indexes differences were observed between the LP and HP groups (Table 3).

Correlation with oxygen consumption was significant for all the indexes studied, although the strength of the correlation varied, being relatively low for PCI $(r=0.38 ; P<0.01,95 \%$ CI $0.11-0.60)$ and moderate for THBI $(r=0.58, P<0.001,95 \%$ CI $0.36-0.74)$ and PCCI $(r=0.59, P<0.001,95 \%$ CI $0.34-0.73)$. These differences are also evident when we consider the cost of oxygen (Figure 1).

Spearman correlation analysis showed that the indexes with higher association with the lesion level were PCCI $(\rho=-0.531 ; P<0.001$;
95\% CI -0.708 to -0.291$)$ and THBI $(\rho=-0.524 ; P<0.001$; $95 \%$ CI -0.704 to -0.282$)$, compared with PCI $(\rho=-0.450$; $P<0.01 ; 95 \%$ CI -0.651 to -0.190$)$. Pearson's correlation analysis showed significant association between oxygen cost, all indexes and lesion level (Figure 2).

\section{DISCUSSION}

We investigated the validity of three HR indexes to measure energy cost during wheelchair propulsion, using a non-random sample of patients with SCI. Comparing the indexes with oxygen cost, we found both weak and moderate correlations in various analyses, with the more significant values found for the THBI and PCCI. There were also significant correlations when comparing the indexes with lesion level. These results seem to indicate that HR indexes, particularly THBI and PCCI, may be used in clinical practice to evaluate the energy cost for these patients. It is noteworthy that we could find no reports of the use of the THBI or PCCI being investigated in this context.

Of the investigated indexes, the PCI had the weakest correlation with oxygen cost, indicating that individuals with higher oxygen consumption did not necessarily exhibit a greater change in HR. This may be explained by the similarity in HR changes between the TP and LP groups. The TP group would have a reduced sympathetic

Table 3 Mean (s.d.) and range of metabolic and performance parameters in groups

\begin{tabular}{|c|c|c|c|c|}
\hline & Tetraplegia & High paraplegia & Low paraplegia & $A / l$ \\
\hline & C6-C8, & T1-T6, & $T 7-L 3$ & C6-L3, \\
\hline & $\mathrm{N}=15$ & $\mathrm{~N}=17$ & $\mathrm{~N}=16$ & $N=48$ \\
\hline \multirow[t]{2}{*}{ Distance, m } & $230.9(67.7)^{a, b}$ & $305.2(85.7)$ & $338.4(62.0)$ & $293.0(84.1)$ \\
\hline & $78-350$ & 208-560 & 260-468 & 78-560 \\
\hline \multirow[t]{2}{*}{ Speed $\left(\mathrm{m} \mathrm{min}^{-1}\right)$} & $42.8(12.6)^{a, b}$ & $57.6(15.5)$ & $64.0(11.6)$ & $55.1(15.8)$ \\
\hline & $16.2-65.7$ & $37.8-104.4$ & $47.0-88.0$ & $16.2-104.4$ \\
\hline \multicolumn{5}{|c|}{ Oxygen uptake- $\mathrm{VO}_{2}\left(\mathrm{~m} \mathrm{~kg}^{-1} \mathrm{~min}^{-1}\right)$} \\
\hline \multirow[t]{2}{*}{ Basal } & $2.9(0.7)^{b}$ & $3.4(0.6)$ & $3.5(0.6)$ & $3.3(0.6)$ \\
\hline & $2.0-4.0$ & $2.3-4.9$ & $2.9-5.3$ & $2.0-5.3$ \\
\hline \multirow[t]{2}{*}{ Exercise } & $6.2(1.69)^{\mathrm{b}}$ & $7.3(1.77)$ & $7.7(1.6)$ & $7.1(1.76)$ \\
\hline & $3.6-8.9$ & $4.9-10.5$ & $5.7-12.4$ & $6.0-12.0$ \\
\hline \multirow[t]{2}{*}{$\Delta \%$} & $139.3(66.1)$ & $144.0(52.2)$ & $145.1(63.9)$ & $142.9(59.5)$ \\
\hline & $55-271.2$ & 73.15-211.8 & $69.4-290.3$ & $55.1-290.3$ \\
\hline \multirow[t]{2}{*}{ Oxygen cost $\left(\mathrm{ml} \mathrm{kg}^{-1} \mathrm{~m}^{-1}\right)$} & $0.17(0.05)^{b}$ & $0.14(0.02)$ & $0.13(0.02)$ & $0.15(0.4)$ \\
\hline & $0.11-0.29$ & $0.10-0.17$ & $0.10-0.18$ & $0.10-0.29$ \\
\hline \multicolumn{5}{|l|}{ Heart rate (beat min ${ }^{-1}$ ) } \\
\hline \multirow[t]{2}{*}{ Basal } & 79.6 (14.7) & $84.4(16.4)$ & $88.3(12.3)$ & $84.2(14.7)$ \\
\hline & $63-112$ & 61-117 & 64-109 & 61-117 \\
\hline \multirow[t]{2}{*}{ Exercise } & 107.7 (19.6) & $122.5(22.7)$ & $112.6(19.3)$ & $114.6(21.1)$ \\
\hline & $81-147$ & 91-168 & 74-157 & $74-168$ \\
\hline \multirow[t]{2}{*}{$\Delta \%$} & $25.6(8.5)$ & $30.5(10.2)^{c}$ & $20.8(8.3)$ & $25.7(9.8)$ \\
\hline & 8.9-37.9 & 11.7-56.0 & $9.5-34.0$ & $8.9-56.0$ \\
\hline \multicolumn{5}{|l|}{ Heart beat indexes (beat $\min ^{-1}$ ) } \\
\hline \multirow[t]{2}{*}{$\mathrm{PCl}$} & $0.8(0.6)^{b}$ & $0.7(0.3)$ & $0.4(0.2)$ & $0.6(0.5)$ \\
\hline & $0.3-2.8$ & $0.3-1.7$ & $0.1-0.8$ & $0.1-2.8$ \\
\hline \multirow[t]{2}{*}{ THBI } & $2.8(1.4)^{b}$ & $2.2(0.6)$ & $1.8(0.4)$ & $2.2(1.0)$ \\
\hline & $1.8-7.4$ & $1.2-3.7$ & $1.0-2.3$ & $1.0-7.4$ \\
\hline \multirow[t]{2}{*}{$\mathrm{PCCl}$} & $2.8(1.5)^{b}$ & $2.2(0.6)$ & $1.8(0.3)$ & $2.3(1.0)$ \\
\hline & $1.8-7.7$ & $1.3-3.6$ & $1.0-2.3$ & $1.0-7.7$ \\
\hline
\end{tabular}

Abbreviations: $\mathrm{PCCl}$, propulsion cardiac cost index; $\mathrm{PCl}$, physiological cost index; THBI, total heart beats index; $\Delta \%$, percentage of variation between rest and exercise.

a $P<0.017$, tetraplegia $\times$ high paraplegia.

${ }^{\mathrm{b}} P<0.017$, tetraplegia $\times$ low paraplegia.

${ }^{c} P<0.017$, high paraplegia $\times$ low paraplegia. 


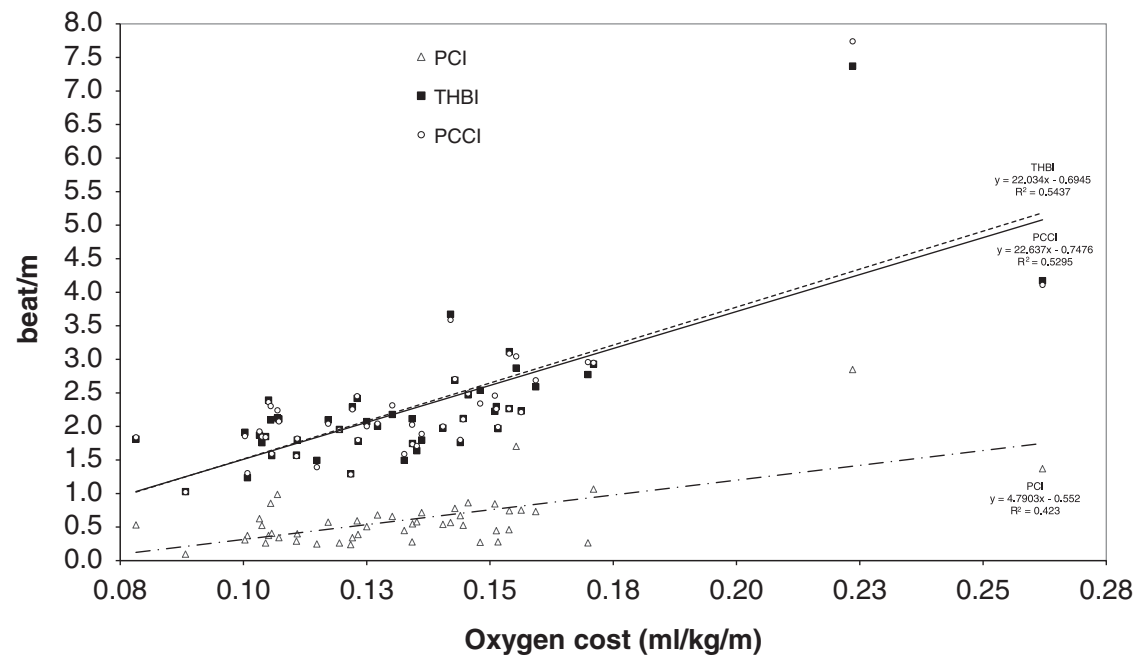

Figure 1 Correlation between physiological cost index (PCI; $P<0.001)$, total heart beat index (THBI; $P<0.001)$ and propulsion cardiac cost index (PCCI; $P<0.001)$ and oxygen cost, during wheelchair propulsion at a comfortable speed in patients with $\mathrm{SCl}(n=48)$.

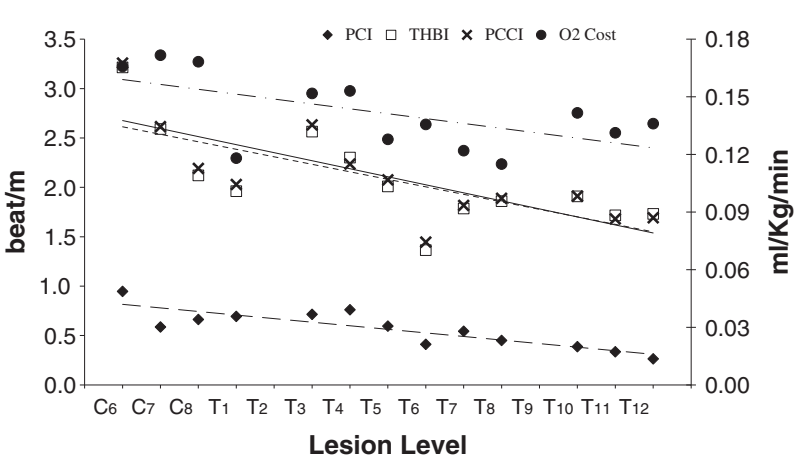

Figure 2 Pearson correlation of oxygen cost $(r=-0.6078, P=0.028)$ physiological cost index $(\mathrm{PCl} ; r=-0.8636, P<0.001)$, total heart beat index (THBI; $r=-0.7284, P=0.005)$ and propulsion cardiac cost index (PCCl; $r=-0.7431, P=0.004)$ with lesion level.

stimulation, likely to lead to consequent limitation of the chronotropic response of the heart, and also a reduced metabolic rate, because of their lower mass of active skeletal muscle. ${ }^{15}$ For the LP group, the exercise used was rated as 'mild physical activity' $(<3.0$ metabolic equivalent of task), for which the metabolic need does not demand a haemodynamic adjustment sufficient to produce tachycardia. Considered to be a simple measure, PCI has been widely used to estimate energy cost during physical activity in various clinical conditions, including walking ${ }^{1,16-20}$ and wheelchair locomotion..$^{2,21-28}$ In the latter case, some of the previous reports used different experimental conditions from ours, making comparisons difficult. The type of wheelchair, ${ }^{2,24}$ the use of mechanical wheelchair propulsion ${ }^{2,25,27}$ and the differences in the studied samples $^{24}$ are some of these discrepancies. Despite of the fact that other reports recommend $\mathrm{PCI},{ }^{2}$ our results question its validity for assessing energy expenditure during wheelchair propulsion in patients with SCI.

By contrast, THBI showed a correlation with oxygen consumption that was very close to that observed for the PCCI that has greater applicability, because it can be calculated using the average HR, which is easily obtained using a cardiac monitor. To obtain the total number of heart beats, which is necessary for the THBI calculation, there are two options: to use a cardiac monitor to measure the HR directly (the method used in the present study), or to calculate the total number from the mean HR during exercise multiplied by the effort time, which implies the need for additional precalculation.

Cardiac indexes can have two uses in clinical practice. First, they can be used to assess energy expenditure during wheelchair propelling under different conditions, such as before and after training or adjustment on a wheelchair. They can also be used, but with caution, to assess a patient's physical condition in relation to his lesion level. Thus using the mean and s.d. for each group, we calculated the PCCI upper limit of the 95\% CI for the full group, TP, LP and HP sub-groups, which were 2.6, 3.6, 2.0 and 2.0 beats $\mathrm{min}^{-1}$, respectively.

Being consistent with evidence that individuals with tetraplegia have less physical capacity than those with paraplegia, ${ }^{29}$ our results correlated significantly with lesion level. We found evidence that the higher the injury level, the greater the energy cost involved in pushing the wheelchair.

One of the factors that hamper a propulsion study is the difference between patients in terms of skill or metabolic capacity for exercise. ${ }^{7}$ For these individuals, we controlled the differences by allowing participants to self-select their comfortable speed, as also considered in other studies. ${ }^{10,12,17,30-34}$ We did not standardize speed but opted instead to assess the way patients routinely moved, reflecting their daily functionality. In addition, using a comfortable speed (submaximal activity from the energy viewpoint) makes a steady-state analysis of the variables possible. Both the speed and the distance travelled in $5 \mathrm{~min}$ showed a significant correlation with our gold standard of oxygen consumption (data not shown). The average speed of our subjects was similar to that in previous studies. ${ }^{26,35}$

\section{Study limitations}

One of the limitations of our study is the absence of information regarding the length of wheelchair use by our surveyed patients before assessment. Previous publications have shown a possible influence of this factor in wheelchair performance. ${ }^{36}$ Mechanical efficiency of propulsion, which depends on user ability, is lower in the newly injured person. ${ }^{36}$ During the rehabilitation process, patients are encouraged to be independent in their daily mobility. Length of wheelchair use is expected to meliorate mechanical efficiency because the patient improves their propulsion techniques, strength 
and cardiovascular fitness. Because of the individual convalescence period, the length of wheelchair use does not necessarily correspond to the length of the injury. However, we believe that the length of the injury can be equivalent to the length of wheelchair use. Additionally, we observed no differences between the groups with regard to this issue.

Another possible limitation refers to the SCI classification. Despite our caution in including only individuals with complete motor lesions (AIS A or B), it is possible that we might have included people with undamaged autonomic nervous system nerve fibres, specifically the sympathetic nervous system, excluding the parasympathetic nervous system (mediated through the vagus nerve, 10th cranial nerve) which is unaffected by SCI. This aspect would influence the HR, which was the object of our study. However, only two patients with tetraplegia had the classification AIS B, and these did not show any discrepancy in their HR.

Because of technical problems, we carried out the tests in two types of closed paths. The seven first tests (two patients with TP, one with HP and four with LP) were performed in closed paths of $70 \mathrm{~m}$ in length. Because the layout of the track may change the results, depending on the number of manoeuveres required, ${ }^{37}$ we compared these results with the later results, collected over a $30 \mathrm{~m}$ course. We found that distance, speed and oxygen consumption were in fact higher in the 30-m course than in the earlier results from the track of $70 \mathrm{~m}$, probably because of the relatively large number of patients with LP in the latter. However, HR values, index results and oxygen use did not differ among patients who performed the assessment over $30 \mathrm{~m}$ and those who performed it over $70 \mathrm{~m}$.

Another possible criticism on this study is the variability in parameters, such as time of injury, age, body weight and body mass index in the studied subjects, and their possible influence on the results. The anthropometric characteristics and age of the participants were similar, which made them comparable to each other and a better reflection of the clinical reality. ${ }^{10,38}$ This spectrum of variation was intentional, and the main objective of this variability was to verify the external validity (that is, applicability) of the study. For the same reason, other potential variables of interest between participants, such as smoking habit, use of alcohol or illicit drugs, length of wheelchair use, and other levels of physical activity, were not systematically considered.

In the construct validation, although the level of injury is an ordinal variable, we also chose to maintain the analysis with the Pearson's coefficient. This approach allowed for the display of the regressions lines in Figure 2 (injury level vs oxygen cost and indexes).

For the applicability of our study, clinical practice requires simple and low-cost means for the evaluation of patients in rehabilitation centres. The importance of evaluating the physical condition of individuals with SCI has been emphasized in the literature, especially in the assessments of the risk of cardiovascular disease associated with the reduced physical capacity of this population. ${ }^{29,39}$ Clinical parameters, such as those studied here, may be useful for the monitoring and evaluating of those aspects. A cardiac monitor is accessible and easy to use. In addition, propelling a wheelchair for $5 \mathrm{~min}$ at a comfortable pace is a practical and short test, which is able to evaluate the expended energy during sub-maximal activity, and can be used for people with lesions below C6 who have different levels of physical fitness.

\section{CONCLUSION}

Of the three indexes assessed, PCI showed only a weak correlation with oxygen consumption, thus its use in the context assessed here should be reviewed. We found both THBI and PCCI to be valid measures for assessing energy expenditure in patients with SCI during wheelchair propulsion. In addition, these indexes were associated with lesion level, showing that, from a biological viewpoint, they are able to monitor variations in oxygen consumption according to the degree of disability. From a clinical perspective, we believe that PCCI is the best method for daily evaluating patients with SCI, because in addition to producing the highest correlation with the gold standard and the lesion level it is the easiest to use. Our results provide new evidence and perspectives regarding energy expenditure in patients with traumatic SCI. Research into other test properties, such as reliability and responsiveness, in the same population and under the same conditions, will be our next subject of study.

\section{DATA ARCHIVING}

There were no data to deposit.

\section{CONFLICT OF INTEREST}

The authors declare no conflict of interest.

\section{DISCLAIMER}

We certify that no party having a direct interest in the results of the research supporting this article has or will confer a benefit on us or on any organization with which we are associated.

1 Fisher SV, Gullickson G Jr. Energy cost of ambulation in health and disability: a literature review. Arch Phys Med Rehabil 1978; 59: 124-133.

2 Mukherjee G, Samanta A. Evaluation of ambulatory performance of the arm propelled three-wheeled chair using heart rate as a control index. Disabil Rehabil 2000; 22: 464-470.

3 van der Woude LH, Dallmeijer AJ, Janssen TW, Veeger D. Alternative modes of manual wheelchair ambulation: an overview. Am J Phys Med Rehabil 2001; 80: 765-777.

4 van der Woude LH, Veeger HE, Dallmeijer AJ, Janssen TW, Rozendaal LA. Biomechanics and physiology in active manual wheelchair propulsion. Med Eng Phys 2001; 23: 713-733.

5 Boyd R, Fatone S, Rodda J, Olesch C, Starr R, Cullis E et al. High- or low-technology measurements of energy expenditure in clinical gait analysis? Dev Med Child Neurol 1999; 41: 676-682

6 MacGregor J. The evaluation of patient performance using long-term ambulatory monitoring technique in the domiciliary environment. Physiotherapy 1981; 67: 30-33.

7 McArdle WD, Katch FI, Katch VL. Exercise Physiology: Nutrition, Energy, and Human Performance. Lippincott Williams \& Wilkins, 2010.

8 Rose J, Gamble JG, Medeiros J, Burgos A, Haskell WL. Energy cost of walking in normal children and in those with cerebral palsy: comparison of heart rate and oxygen uptake. J Pediatr Orthop 1989; 9: 276-279.

9 Bar-On ZH, Nene AV. Relationship between heart rate and oxygen uptake in thoracic level paraplegics. Paraplegia 1990; 28: 87-95.

10 Hood VL, Granat MH, Maxwell DJ, Hasler JP. A new method of using heart rate to represent energy expenditure: the Total Heart Beat Index. Arch Phys Med Rehabil 2002; 83: 1266-1273.

11 Valent LJ, Dallmeijer AJ, Houdijk H, Slootman J, Janssen TW, Hollander AP et al. The individual relationship between heart rate and oxygen uptake in people with a tetraplegia during exercise. Spinal Cord 2007; 45: 104-111.

12 Bernardi M, Macaluso A, Sproviero E, Castellano V, Coratella D, Felici F et al. Cost of walking and locomotor impairment. J Electromyogr Kinesiol 1999; 9: 149-157.

13 Maynard FM Jr, Bracken MB, Creasey G, Ditunno JF Jr, Donovan WH, Ducker TB et al. International Standards for Neurological and Functional Classification of Spinal Cord Injury. American Spinal Injury Association. Spinal Cord 1997; 35: 266-274.

14 Janssen TW, Dallmeijer AJ, Veeger DJ, van der Woude LH. Normative values and determinants of physical capacity in individuals with spinal cord injury. J Rehabil Res Dev 2002; 39: 29-39.

15 Van Loan MD, McCluer S, Loftin JM, Boileau RA. Comparison of physiological responses to maximal arm exercise among able-bodied, paraplegics and quadriplegics. Paraplegia 1987; 25: 397-405.

16 Nene AV, Patrick JH. Energy cost of paraplegic locomotion using the ParaWalker-electrical stimulation 'hybrid' orthosis. Arch Phys Med Rehabil 1990; 71: 116-120.

17 IJzerman MJ, Baardman G, van 't Hof MA, Boom HB, Hermens HJ, Veltink PH. Validity and reproducibility of crutch force and heart rate measurements to assess energy expenditure of paraplegic gait. Arch Phys Med Rehabil 1999; 80: 1017-1023. 
18 Corry IS, Duffy CM, Cosgrave AP, Graham HK. Measurement of oxygen consumption in disabled children by the Cosmed K2 portable telemetry system. Dev Med Child Neurol 1996; 38: 585-593.

19 Rose J, Gamble JG, Lee J, Lee R, Haskell WL. The energy expenditure index: a method to quantitate and compare walking energy expenditure for children and adolescents. $J$ Pediatr Orthop 1991; 11: 571-578.

20 Rose J, Gamble JG, Burgos A, Medeiros J, Haskell WL. Energy expenditure index of walking for normal children and for children with cerebral palsy. Dev Med Child Neurol 1990; 32: 333-340.

21 Mukherjee G, Bhowik P, Samanta A. Energy cost of manual wheelchair propulsion at different speeds. Int J Rehabil Res 2002; 25: 71-75.

22 Hughes B, Sawatzky BJ, Hol AT. A comparison of spinergy versus standard steel-spoke wheelchair wheels. Arch Phys Med Rehabil 2005; 86: 596-601.

23 Mukherjee G, Samanta A. Arm-crank propelled three-wheeled chair: physiological evaluation of the propulsion using one arm and both arm patterns. Int $J$ Rehabil Res 2004; 27: 321-324.

24 Makino K, Wada F, Hachisuka K, Yoshimoto N, Ohmine S. Speed and physiological cost index of hemiplegic patients pedalling a wheelchair with both legs. J Rehabil Med 2005; 37: 83-86.

25 Mukherjee G, Bhowmik P, Samanta A. Physical fitness training for wheelchai ambulation by the arm crank propulsion technique. Clin Rehabil 2001; 15: 125-132.

26 Mukherjee G, Samanta A. Physiological response to the ambulatory performance of hand-rim and arm-crank propulsion systems. J Rehabil Res Dev 2001; 38: 391-399.

27 Mukherjee G, Samanta A. Energy cost and locomotor performance of the low-cost armlever-propelled three-wheeled chair. Int J Rehabil Res 2001; 24: 245-249.

28 Sawatzky BJ, Miller WC, Denison I. Measuring energy expenditure using heart rate to assess the effects of wheelchair tyre pressure. Clin Rehabil 2005; 19: 182-187.

29 Haisma JA, van der Woude LH, Stam HJ, Bergen MP, Sluis TA, Bussmann JB. Physical capacity in wheelchair-dependent persons with a spinal cord injury: a critical review of the literature. Spinal Cord 2006; 44: 642-652.
30 Bailey MJ, Ratcliffe CM. Reliability of physiological cost index measurements in walking normal subjects using steady-state, non-steady-state and post-exercise heart rate recording. Physiotherapy 1995; 81: 618-623.

31 Graham RC, Smith NM, White CM. The reliability and validity of the physiological cost index in healthy subjects while walking on 2 different tracks. Arch Phys Med Rehabil 2005; 86: 2041-2046.

32 Ijzerman MJ, Nene AV. Feasibility of the physiological cost index as an outcome measure for the assessment of energy expenditure during walking. Arch Phys Med Rehabil 2002; 83: 1777-1782.

33 Norman JF, Bossman S, Gardner P, Moen C. Comparison of the energy expenditure index and oxygen consumption index during self-paced walking in children with spastic diplegia cerebral palsy and children without physical disabilities. Pediatr Phys Ther 2004; 16: 206-211.

34 Waters RL, Lunsford BR. Energy cost of paraplegic locomotion. J Bone Joint Surg Am 1985; 67: 1245-1250.

35 Newsam CJ, Mulroy SJ, Gronley JK, Bontrager EL, Perry J. Temporal-spatial characteristics of wheelchair propulsion. Effects of level of spinal cord injury, terrain, and propulsion rate. Am J Phys Med Rehabil 1996; 75: 292-299.

36 de Groot S, Dallmeijer AJ, Kilkens OJ, van Asbeck FW, Nene AV, Angenot EL et al. Course of gross mechanical efficiency in handrim wheelchair propulsion during rehabilitation of people with spinal cord injury: a prospective cohort study. Arch Phys Med Rehabil 2005; 86: 1452-1460.

37 Reid M, Lawrie AT, Hunter J, Warren PM. The effect of steering on the physiological energy cost of wheelchair propulsion. Scand J Rehabil Med 1990; 22. 139-143.

38 Carvalho DC, de Cassia Zanchetta M, Sereni JM, Cliquet A. Metabolic and cardiorespiratory responses of tetraplegic subjects during treadmill walking using neuromuscular electrical stimulation and partial body weight support. Spinal Cord 2005; 43: 400-405.

$39 \mathrm{Hol}$ AT, Eng JJ, Miller WC, Sproule S, Krassioukov AV. Reliability and validity of the six minute arm test for the evaluation of cardiovascular fitness in people with spinal cord injury. Arch Phys Med Rehabil 2007; 88: 489-495. 